\title{
Association of the CACNA2D2 gene with schizophrenia in Chinese Han population
}

\author{
Yingli Fu ${ }^{1,2}$, Na Zhou ${ }^{3}$, Wei Bai ${ }^{1}$, Yaoyao Sun ${ }^{1}$, Xin Chen ${ }^{1}$, Yueying Wang ${ }^{1}$, Mingyuan Zhang ${ }^{1}$, Changgui Kou ${ }^{1}$, \\ Yaqin $\mathbf{Y u}^{1}$, Qiong Yu ${ }^{\text {Corresp. } 1}$ \\ 1 Department of Epidemiology and Statistics,School of Public Health, Jilin University, Changchun, Jilin, China \\ 2 Division of Clinical Research, First Hospital of Jilin University, Changchun, Jilin, China \\ 3 Depart of Pharmacy, School and Hospital of Stomatology, Jilin University, Changchun, Jilin, China \\ Corresponding Author: Qiong Yu \\ Email address: yuqiong@jlu.edu.cn
}

Background. Schizophrenia is a severely complex psychiatric disorder in which $~ 80 \%$ can be explained by genetic factors. Single nucleotide polymorphisms (SNPs) in calcium channel genes are potential genetic risk factors for a spectrum of psychiatric disorders including schizophrenia. This study evaluated the association between SNPs in the voltage-gated calcium channel auxiliary subunit alpha2delta 2 gene (CACNA2D2) and schizophrenia in the Han Chinese population of Northeast China. .

Methods. A total of 761 schizophrenia patients and 775 healthy controls were involved in this casecontrol study. Three SNPs (rs3806706, rs45536634, and rs12496815) of CACNA2D2 were genotyped by the MALDI-TOF-MS technology. Genotype distribution and allele frequency differences between cases and controls were tested by Chi-square $\left(\chi^{2}\right)$ in males and females respectively using software SPSS24.0. Linkage disequilibrium and haplotype analyses were conducted using Haploview4.2. The false discovery rate (FDR) correction was utilized to control for Type I error by R3.2.3.

Results. There was a significant difference in allele frequencies $\left(\chi^{2}=9.545, P_{\text {adj }}=0.006\right)$ and genotype distributions $\left(\chi^{2}=9.275, P_{\text {adj }}=0.006\right)$ of rs45536634 between female schizophrenia patients and female healthy controls after adjusting for multiple comparisons. Minor allele $\mathrm{A}(O R=1.871,95 \% \mathrm{Cl}=1.251-2.798)$ and genotype $\mathrm{GA}+\mathrm{AA}(O R=1.931,95 \% \mathrm{Cl}=1.259-2.963)$ were associated with an increased risk of schizophrenia. Subjects with haplotype AG consisting of rs45536634 and rs12496815 alleles had a higher risk of schizophrenia $(O R=1.91,95 \% C l=1.26-2.90)$ compared those with other haplotypes.

Conclusions. This study provides evidence that CACNA2D2 polymorphisms may influence the susceptibility to schizophrenia in Han Chinese women. 
1 Association of the CACNA2D2 gene with schizophrenia in Chinese Han population

2 Yingli Fu ${ }^{12}, \mathrm{Na} \mathrm{Zhou}^{3}$, Wei Bai ${ }^{1}$, Yaoyao Sun ${ }^{1}$, Xin Chen ${ }^{1}$, Yueying Wang ${ }^{1}$, Mingyuan

3 Zhang $^{1}$, Changgui Kou ${ }^{1}$, Yaqin $\mathrm{Yu}^{1}$, Qiong $\mathrm{Yu}^{1}$

$4{ }^{1}$ Department of Epidemiology and Statistics, School of Public Health, Jilin University,

5 Changchun, Jilin, China

62 Division of Clinical Research, First Hospital of Jilin University, Changchun, Jilin 130021,

7 China

$8{ }^{3}$ Depart of Pharmacy, School and Hospital of Stomatology, Jilin University, Changchun,

9 Jilin, China

10 Corresponding Author:

11 Qiong $\mathrm{Yu}^{1}$

121163 Xinmin Street, Changchun, Jilin, 130021, China.

13 Email address: yuqiong@jlu.edu.cn

14

15

16

17

18

19 
Abstract

Background. Schizophrenia is a severely complex psychiatric disorder in which $\sim 80 \%$ can be explained by genetic factors. Single nucleotide polymorphisms (SNPs) in calcium channel genes are potential genetic risk factors for a spectrum of psychiatric disorders including schizophrenia. This study evaluated the association between SNPs in the voltage-gated calcium channel auxiliary subunit alpha2delta 2 gene $(C A C N A 2 D 2)$ and schizophrenia in the Han Chinese population of Northeast China. 
55

56

57

Keywords: Schizophrenia; CACNA2D2; SNPs; haplotype

\section{Background}

Schizophrenia (SCZ) is a severely debilitating psychiatric disorder characterized by positive and negative symptoms as well as cognitive dysfunction (Allen et al. 2008; Koike et al. 2014). The lifetime risk of schizophrenia is approximately $1 \%$ across the world (Mayilyan et al. 2008), and the lifetime prevalence of adults in China was $0.6 \%$ (Huang et al. 2019). Schizophrenia has a marked impact on the life quality and accounts for approximately $2.8 \%$ of the global burden of diseases reported by the World Health Organization (WHO) in 2001, and the prevalence of schizophrenia disability was $0.41 \%$ in China (Liu et al. 2015).

Genetic and environmental factors may combine to increase schizophrenia risk (Plomin et al. 1994). Genetic factors explain $\sim 80 \%$ of the risk for schizophrenia, and the risk of the schizophrenia decrease as the parental relationship recedes (Zhu et al. 2009). Despite vigorous genome-wide association studies have been conducted to elucidate the common genetic variations associated with the susceptibility to schizophrenia (Børglum et al. 2014; Riley et al. 2009), the etiology of schizophrenia remains obscure, suggesting that additional studies are required to discover the "missing heritability".

The voltage-gated calcium channel auxiliary subunit alpha2delta 2 gene (CACNA2D2), located in 3p21.31 and highly expressed in the brain, encodes a calcium channel protein. Voltage-gated calcium channels are widely distributed throughout the brain and mediate the intracellular Ca2+ influx of synaptic action potentials (Guan et al. 2016). In recent years, the gene encoding voltage-gated calcium channel subunit attracts wide attention in the field of schizophrenia pathogenesis. SNPs in calcium channel genes have been identified as genetic risk factors for a spectrum of psychiatric disorders (Cross-Disorder Group of the Psychiatric Genomics Consortium2013; Cross-Disorder Group of the Psychiatric Genomics Consortium 2014). For example, several studies showed that SNPs of CACNAIC were significantly 
82

83

84

associated with schizophrenia, and the finding has been confirmed in different populations (Gasso et al. 2016; Zhang et al. 2017; Zhu \& Li 2019). Although there are no reported studies on the relationship between $C A C N A 2 D 2$ and schizophrenia, CACNA2D2 may cause other psychiatric disorders (Berridge 2013) and severe neurological diseases (Strupp et al. 2005). In this study, we conducted a genetic association study to examine the association between SNPs of CACNA2D2 and schizophrenia by a case-control study.

\section{Materials and Methods}

\section{Study Population}

A total of 761 patients with schizophrenia from the Mental Hospital of Changchun and 775 healthy controls from the physical examination center of the First Hospital of Jilin University were recruited. All participants were Han Chinese. The patients were diagnosed according to the criteria of the International Statistical Classification of Disease and Related Health Problems, Tenth Revision (ICD-10) independently by at least two experienced psychiatrists. Healthy controls matched the patients by gender and age. All controls had no personal or family history of mental illness. This study was performed under protocols approved by the Ethics Committee of Jilin University, China (2014-05-01). All subjects signed written informed consent before participating in this study, and all experiments were performed in accordance with relevant guidelines and regulations.

\section{DNA Extraction and SNP selection}

Peripheral blood of $5 \mathrm{~mL}$ was collected from each subject, and the genomic DNA was extracted from blood samples using a commercial DNA extraction kit (Kangwei Biotech Company, Beijing, China). SNPs located in the promoter and 3' untranslated region (UTR) of CACNA2D2 were searched in NCBI-SNP (https://www.ncbi.nlm.nih.gov/snp/) and Ensembl (https://asia.ensembl.org/) databases. We predicted the function of these SNPs in SNPinfo (http://snpinfo. niehs.nih.gov/) and searched for minor allele frequency (MAF) each SNP in 1000 Genomes. Finally, we chose three SNPs (MAF > 0.05) located in promoter or 3'UTR regions (rs3806706 in the promoter region and rs45536634 and rs12496815 in the 3' 
109

110

111

112

113

114

115

116

117

118

119

120

121

122

123

124

125

126

127

128

129

130

\section{1}

132

133

134

135

UTR) of CACNA2D2 and predicted to be located in transcription factor binding sites (TFBS).

SNP genotyping was performed using matrix-assisted laser desorption/ionization time of flight mass spectrometry (MALDI-TOF-MS). SNP genotyping reactions were performed in a 384-well Spectro-CHIP using a Mass Array nanodispenser (Sequenom Inc.). The primers for genotyping were designed by AssayDesigner3.1 and were listed in Table 1.

\section{Statistical Analysis}

Pearson's Chi-square $\left(\chi^{2}\right)$ test and Student's t-test were used to test the distribution of sex and age between case and control groups, respectively. The distributions of allele and genotype were analyzed using $\chi^{2}$ tests. The odds ratio $(O R)$ was used to estimate the relative risk of schizophrenia associated with genotypes with minor alleles. The Type I error due to multiple testing was corrected by the false discovery rate (FDR) method. All the above analyses were performed using Software SPSS 24.0 (IBM SPSS, IBM Corp, Armonk, NY, USA), and R version 3.2.3 was used for FDR corrections. The Hardy-Weinberg equilibrium (HWE) test was conducted in the case and control group separately by Goodness of fit $\chi^{2}$ test using online software SNPStats (https://www.snpstats. net/snpstats/start.htm). The linkage disequilibrium (LD) between SNPs was estimated in both females and males separately using Haploview 4.2 (Barrett et al. 2005), and the haplotype analysis was further performed using Haploview. The statistical power for each SNP was calculated according to the MAF of each SNP (rs45536634: 0.073, rs3806706: 0.378, and rs12496815: 0.388). The prevalence of schizophrenia (1\%) was estimated by Quanto 1.2.4 (Gauderman 2002). The OR was set from 1.4 to 2.0. All tests were two-sided and Padj-value less than 0.05 was considered to be statistically significant.

\section{Results}

\section{Demographic Characteristics}

A total of 1,536 subjects were included in this study, comprised of 761 schizophrenia patients $(58.2 \%$ males, mean age $=34.61 \pm 12.02$ years $)$ and 775 healthy controls $(56.2 \%$ males, mean age $=34.74 \pm 11.41$ years $)$. There was no significant difference either in sex $\left(\chi^{2}\right.$ 
$136=0.681, P=0.409)$ or age $(t=0.221, P=0.825)$ between patients and healthy controls. The 137 results of the HWE test were shown in Table 2. All SNPs were in accordance with the HWE 138 in both cases and controls $(P>0.05)$.

\section{The distribution of alleles and genotypes in males and females}

The detection rate of rs45536634, rs12496815 and rs3806706 were 97\%, 92\% and 98\%, respectively. Genotype and allele frequencies of females were depicted in Table 3. A significant difference $\left(P_{\text {ajd }}=0.012\right)$ was observed in allele frequencies of rs45536634 between female schizophrenia patients and female healthy controls. Subjects who carried minor allele A had a 1.9 times higher risk of schizophrenia than those homozygous for the major G allele. Similarly, a significant difference $\left(P_{\text {ajd }}=0.006\right)$ was observed in the genotype distribution in females, and subjects with the minor allele $(\mathrm{GA}+\mathrm{AA})$ has an increased risk of schizophrenia when compared those with genotype $\mathrm{GG}(O R=1.931,95 \% C I=1.259-2.963)$. These associations were found only in females, but not in males. In the male group, there was a difference between cases and controls in the genotype distribution of rs3806706 $(P=0.02)$; however, after adjusting for multiple testing, the difference was not significant $\left(P_{\mathrm{ajd}}=0.12\right)$ 151 (Table 4).

152

\section{LD and Haplotype Analysis}

As shown in Figure 1, the LD analysis of rs45536634 and rs12496815 in CACNA2D2 showed that the D' values were equal to 1 in both female and male groups. According to the results of LD analysis, haplotype association analyses of rs45536634-rs12496815 were conducted in females and males respectively, and the results are shown in Table 5. Three common haplotypes were estimated to have a frequency $>1 \%$, and haplotype AG was significantly associated with schizophrenia $\left(O R=1.91, P_{\mathrm{adj}}=0.0096\right)$ in females.

\section{Statistical power}

The statistical power for rs45536634, rs12496815, and rs3806706 were 0.675-0.999, 0.8720.999, and 0.878-0.999, respectively, if the OR varied from 1.4 to 2.0.

\section{Discussion}


The association between variants of a number of genes and schizophrenia has been

164

165

166

167

168

169

170

171

172

173

174

175

176

177

reported in previous studies. To the best of our knowledge, this is the first report of a significant association between rs45536634 of CACNA2D2 and schizophrenia in females of the Northeast Han Chinese population.

It is known that $\mathrm{Ca} 2+$ ion represents one of the most important second messengers in the brain and plays an essential role in neuronal development, synaptic transmission and plasticity, besides regulating various metabolic pathways (Striessnig et al. 2006). Notably, as demonstrated by several studies, the $\mathrm{Ca} 2+$ homeostasis disorder is associated with many pathological mechanisms, especially those related to neurodegenerative disorders, such as schizophrenia, Alzheimer's disease, and bipolar disorder(Berridge 2013; Sulzer \& Surmeier 2013). CACNA2D2 encodes the Alpha 2 delta 2 subunit of voltage-gated calcium channel (Tedeschi et al. 2016) which is a key signaling element, allowing changes in membrane potential to control a large number of $\mathrm{Ca} 2+$ dependent neurotransmitter release and neuronal plasticity in electrically excitable cells (Striessnig et al. 2006). A study conducted by Villela et al. showed that the copy number change in $C A C N A 2 D 2$ was a risk factor for Alzheimer's Disease (Villela et al. 2016).

Moreover, $C A C N A 1 C$, a gene in the same family as $C A C N A 2 D 2$, has been repeatedly confirmed as one of the susceptibility genes for schizophrenia in various populations (Guan et al. 2014; He et al. 2014). In addition, Zhang et al. conducted a review research on calcium channel genes associated with schizophrenia in the Han Chinese population and found that $C A C N A 1 C, C A C N B 2, C A C N A 2 D 1$ and $C A C N A 2 D 3$ were related to schizophrenia (Zhang et al. 2018).

The sex-specific molecular phenotype of schizophrenia was observed in previous studies. A study conducted by Oumaima et al. indicated that minor alleles of SNPs in genes LTA and TNFA were over-represented in male schizophrenia patients but not in female schizophrenia patients (Inoubli et al. 2018). Jemli et al. researched the association between the functional polymorphism of IFNGR2 with schizophrenia and found the IFNGR2 Q64R 
190

191

192

193

194

195

polymorphism was associated with schizophrenia in males (Jemli et al. 2017). The study conducted by Yang Guang et.al showed that the genotypes and allele distributions of rs3087494 in PLA2G12A were significantly associated with schizophrenia in males, but not in females (Yang et al. 2016). Another study focused on sex-specific molecular phenotypes found that eight genes showed a differential expression in female and male schizophrenia patients (Ramsey et al. 2013).

For a better understanding of the association between schizophrenia and $C A C N A 2 D 2$, a more in-depth investigation - haplotype analysis was carried out to determine whether the combination of specific alleles was associated with the schizophrenia risk. The AG haplotype, consisted of rs44536634 and rs12496815 alleles, was correlated with an increased risk of schizophrenia in Han Chinese women. The haplotype analysis not only confirmed the association between rs44536634 and schizophrenia, but also supported that rs44536634 allele A was associated with an increased risk of schizophrenia in females. Furthermore, our research provided an evidence to support the distinct molecular phenotypes of schizophrenia patients with different gender, as reported in previous studies.(Ben Nejma et al. 2013; Jemli et al. 2017; Ramsey et al. 2013).

In this study, several limitations should be considered. Firstly, our study was performed at a single center and only three SNPs were analyzed, it ignored SNPs in other genes that may be associated with schizophrenia. Secondly, the study is limited to interpreting the causal relationship between genetic risk factors and schizophrenia as this is a cross-sectional study. Furthermore, the representative of this study was limited to the adults of Northeast China because the samples were collected from Jilin Province. Finally, we lost some demographic covariates of the controls when analyzing the association between $C A C N A 2 D 2$ SNP polymorphism and schizophrenia patients due to the difficulty of demographic characteristics collection. Large-scale examination with more demographic characteristics is warranted to further examine the association between $C A C N A 2 D 2$ and schizophrenia.

\section{Conclusion}


219 polymorphisms might influence the susceptibility to schizophrenia in Han Chinese women variants.

\section{References}

Allen NC, Bagade S, McQueen MB, Ioannidis JP, Kavvoura FK, Khoury MJ, Tanzi RE, and Bertram L. 2008. Systematic meta-analyses and field synopsis of genetic association studies in schizophrenia: the SzGene database. Nat Genet 40:827-834. 10.1038/ng.171

Børglum AD, Demontis D, Grove J, Pallesen J, Hollegaard MV, Pedersen CB, Hedemand A, Mattheisen M, investigators G, Uitterlinden A, Nyegaard M, Ørntoft T, Wiuf C, Didriksen M, Nordentoft M, Nöthen MM, Rietschel M, Ophoff RA, Cichon S, Yolken RH, Hougaard DM, Mortensen PB, and Mors O. 2014. Genomewide study of association and interaction with maternal cytomegalovirus infection suggests new schizophrenia loci. Mol Psychiatry 19:325-333. 10.1038/mp.2013.2

Barrett JC , Fry B , Maller J , and Daly MJ. 2005. Haploview: analysis and visualization of LD and haplotype maps. Bioinformatics 21:263-265. 10.1093/bioinformatics/bth457

Ben Nejma M, Zaabar I, Zaafrane F, Thabet S, Mechri A, Gaha L, Ben Salem K, and Bel Hadj Jrad B. 2013. A genderspecific association of interleukin 1 receptor antagonist polymorphism with schizophrenia susceptibility. Acta Neuropsychiatr 25:349-355. 10.1017/neu.2012.32

Berridge MJ. 2013. Dysregulation of neural calcium signaling in Alzheimer disease, bipolar disorder and schizophrenia. Prion 7:2-13. 10.4161/pri.21767

Cross-Disorder Group of the Psychiatric Genomics Consortium. 2013. Identification of risk loci with shared effects on five major psychiatric disorders: a genome-wide analysis. Lancet 381:1371-1379. 10.1016/s01406736(12)62129-1

Cross-Disorder Group of the Psychiatric Genomics Consortium.2014. Biological insights from 108 schizophreniaassociated genetic loci. Nature 511:421-427. 10.1038/nature13595

Gasso P, Sanchez-Gistau V, Mas S, Sugranyes G, Rodriguez N, Boloc D, de la Serna E, Romero S, Moreno D, Moreno C, Diaz-Caneja CM, Lafuente A, and Castro-Fornieles J. 2016. Association of CACNA1C and SYNE1 in offspring of patients with psychiatric disorders. Psychiatry Res 245:427-435. 10.1016/j.psychres.

Gauderman WJ. 2002. Sample size requirements for association studies of gene-gene interaction. Am j epidemiol 155:478-484. 10.1093/aje/155.5.478

Guan F, Zhang B, Yan T, Li L, Liu F, Li T, Feng Z, Zhang B, Liu X, and Li S. 2014. MIR137 gene and target gene CACNA1C of miR-137 contribute to schizophrenia susceptibility in Han Chinese. Schizophr Res 152:97-104. 10.1016/j.schres.

Guan F, Zhang T, Liu X, Han W, Lin H, Li L, Chen G, and Li T. 2016. Evaluation of voltage-dependent calcium channel 
254

255

256

257

258

259

260

261

262

263

264

265

266

267

268

269

270

271

272

273

274

275

276

277

278

279

280

281

282

283

284

285

286

287

288

289

290

291

292

293

294 gamma gene families identified several novel potential susceptible genes to schizophrenia. Sci Rep 6:24914. 10.1038/srep24914

He K, An Z, Wang Q, Li T, Li Z, Chen J, Li W, Wang T, Ji J, Feng G, Lin H, Yi Q, and Shi Y. 2014. CACNA1C, schizophrenia and major depressive disorder in the Han Chinese population. Br J Psychiatry 204:36-39. 10.1192/bjp.bp.113.126979

Huang Y, Wang Y, Wang H, Liu Z, Yu X, Yan J, Yu Y, Kou C, Xu X, Lu J, Wang Z, He S, Xu Y, He Y, Li T, Guo W, Tian H, Xu G, Xu X, Ma Y, Wang L, Wang L, Yan Y, Wang B, Xiao S, Zhou L, Li L, Tan L, Zhang T, Ma C, Li Q, Ding H, Geng H, Jia F, Shi J, Wang S, Zhang N, Du X, Du X, and Wu Y. 2019. Prevalence of mental disorders in China: a cross-sectional epidemiological study. Lancet Psychiatry 6:211-224. 10.1016/s22150366(18)30511-x

Inoubli O, Jemli A, Ben Fredj S, Mechri A, Gaha L, and Bel Hadj Jrad B. 2018. Haplotypes of TNFalpha/beta Genes Associated with Sex-Specific Paranoid Schizophrenic Risk in Tunisian Population. Dis Markers 2018:3502564. 10.1155/2018/3502564

Jemli A, Inoubli O, Trifa F, Mechri A, Zaafrane F, Gaha L, and Jrad BB. 2017. IFNGR2 genetic polymorphism associated with sex-specific paranoid schizophrenia risk. Nord J Psychiatry 71:42-47. 10.1080/08039488.2016.1216595

Koike S, Bundo M, Iwamoto K, Suga M, Kuwabara H, Ohashi Y, Shinoda K, Takano Y, Iwashiro N, Satomura Y, Nagai T, Natsubori T, Tada M, Yamasue H, and Kasai K. 2014. A snapshot of plasma metabolites in first-episode schizophrenia: a capillary electrophoresis time-of-flight mass spectrometry study. Transl Psychiatry 4:e379. 10.1038/tp.2014.19

Liu T, Zhang L, Pang L, Li N, Chen G, and Zheng X. 2015. Schizophrenia-related disability in China: prevalence, gender, and geographic location. Psychiatr Serv 66:249-257. 10.1176/appi.ps.201400032

Mayilyan KR, Weinberger DR, and Sim RB. 2008. The complement system in schizophrenia. Drug News Perspect 21:200-210. 10.1358/dnp.2008.21.4.1213349

Plomin R, Owen MJ, and McGuffin P. 1994. The genetic basis of complex human behaviors. Science 264:1733-1739. Ramsey JM, Schwarz E, Guest PC, van Beveren NJ, Leweke FM, Rothermundt M, Bogerts B, Steiner J, and Bahn S. 2013. Distinct molecular phenotypes in male and female schizophrenia patients. PLoS One 8:e78729. 10.1371/journal.pone.0078729

Riley B, Thiselton D, Maher BS, Bigdeli T, Wormley B, McMichael GO, Fanous AH, Vladimirov V, O'Neill FA, Walsh D, and Kendler KS. 2009. Replication of association between schizophrenia and ZNF804A in the Irish CaseControl Study of Schizophrenia sample. Mol Psychiatry 15:29. 10.1038/mp.2009.109.

https://www.nature.com/articles/mp2009109\#supplementary-information

Striessnig J, Koschak A, Sinnegger-Brauns MJ, Hetzenauer A, Nguyen NK, Busquet P, Pelster G, and Singewald N. 2006. Role of voltage-gated L-type Ca2+ channel isoforms for brain function. Biochem Soc Trans 34:903909. 10.1042/bst0340903

Strupp M, Kalla R, Freilinger T, Dichgans M, and Brandt T. 2005. Dysfunction of the brain calcium channel CaV2.1 in absence epilepsy and episodic ataxia--a comment. Brain 128:E32; author reply E33. 10.1093/brain/awh440

Sulzer D, and Surmeier DJ. 2013. Neuronal vulnerability, pathogenesis, and Parkinson's disease. Mov Disord 28:715-724. 10.1002/mds.25187

Tedeschi A, Dupraz S, Laskowski CJ, Xue J, Ulas T, Beyer M, Schultze JL, and Bradke F. 2016. The Calcium Channel 
295

296

297

298

299

300

301

302

303

304

305

306

307

308

309

310

311

312

313

314

315

316

317

318

319

320

\section{3}

\section{9}

Subunit Alpha2delta2 Suppresses Axon Regeneration in the Adult CNS. Neuron 92:419-434.

10.1016/j.neuron.2016.09.026

Villela D, Suemoto CK, Pasqualucci CA, Grinberg LT, and Rosenberg C. 2016. Do Copy Number Changes in CACNA2D2, CACNA2D3, and CACNA1D Constitute a Predisposing Risk Factor for Alzheimer's Disease? Front Genet 7:107. 10.3389/fgene.2016.00107

Yang G, Xu H, Zhang H, Yu Q, Wu Y, Shi J, Rao W, You Y, and Kou C. 2016. Association between PLA2G12A Polymorphisms and Schizophrenia in a Han Chinese Population from Northeast China. Plos One .11(7): e0159584. 10.1371/journal.pone.0159584

Zhang SY, Hu Q, Tang T, Liu C, Li CC, Yang XG, Zang YY, and Cai WX. 2017. Role of CACNA1C gene polymorphisms and protein expressions in the pathogenesis of schizophrenia: a case-control study in a Chinese population. Neurol Sci 38:1393-1403. 10.1007/s10072-017-2963-0

Zhang T, Zhu L, Ni T, Liu D, Chen G, Yan Z, Lin H, Guan F, and Rice JP. 2018. Voltage-gated calcium channel activity and complex related genes and schizophrenia: A systematic investigation based on Han Chinese population. J Psychiatr Res 106:99-105. 10.1016/j.jpsychires.2018.09.020

Zhu X, and Li R. 2019. CACNA1C Polymorphism (rs2283291) Is Associated with Schizophrenia in Chinese Males: A Case-Control Study. Dis Markers 2019:8062397. 10.1155/2019/8062397

Zhu Y, Kalbfleisch T, Brennan MD, and Li Y. 2009. A MicroRNA gene is hosted in an intron of a schizophreniasusceptibility gene. Schizophr Res 109:86-89. 10.1016/j.schres.2009.01.022

(1)

5

6

17

18




\section{Table $\mathbf{1}$ (on next page)}

Primers for polymerase chain reaction 
1

Table 1. Primers for polymerase chain reaction

\begin{tabular}{lll}
\hline SNP & Primer sequence(5'-3') \\
\hline rs12496815 & F: & ACGTTGGATGTGGTTTTGGCACCAGTGCGT \\
& R: & ACGTTGGATGTGGCACCCAAATCACATCTC \\
rs3806706 & F: & ACGTTGGATGTGAGCTCAACAGCTGCCTTC \\
& R: & ACGTTGGATGGTCCAGCAAACAGGTAAGAG \\
rs45536634 & F: & ACGTTGGATGCAATGTATGTCAAGGGCCTG \\
& R: & ACGTTGGATGGAGTCCCACTTAGTGCTCTG \\
\hline
\end{tabular}

2 


\section{Table 2 (on next page)}

Test of HWE for case and control groups

Ho: observed heterozygosity; He: expected heterozygosity. 
1 Table 2. Test of HWE for case and control groups

\begin{tabular}{|c|c|c|c|c|c|c|c|c|c|}
\hline \multirow{2}{*}{ Gene } & \multirow{2}{*}{ SNP } & \multicolumn{4}{|l|}{ case } & \multicolumn{4}{|c|}{ control } \\
\hline & & $\mathrm{H}_{0}$ & $\mathrm{He}$ & $\chi^{2}$ & $P$ & $\mathrm{H}_{0}$ & $\mathrm{He}$ & $\chi^{2}$ & $P$ \\
\hline \multirow[t]{3}{*}{$C A C N A 2 D 2$} & rs45536634 & 0.172 & 0.171 & 0.024 & 0.9 & 0.127 & 0.137 & 2.42 & 0.12 \\
\hline & rs 12496815 & 0.469 & 0.497 & 2.126 & 0.1 & 0.498 & 0.499 & 0.002 & 0.968 \\
\hline & rs3806706 & 0.458 & 0.437 & 1.66 & 0.2 & 0.403 & 0.422 & 1.583 & 0.208 \\
\hline
\end{tabular}

2 Ho: observed heterozygosity; He: expected heterozygosity. 


\section{Table 3(on next page)}

Genotype and allele distributions of CACNA2D2 SNPs in female

$P_{\text {adj }}$ represent $P$ corrected by FDR

$* P_{\text {adj }}<0.05$ 

Table 3. Genotype and allele distributions of $C A C N A 2 D 2$ SNPs in female.

\begin{tabular}{llllllll}
\hline SNPs & Genotype & Case & Control & $\chi^{2}$ & $P$ & $P_{\text {adj }}$ & OR(95\%CI) \\
\hline rs3806706 & GG & 140 & 158 & 0.032 & 0.858 & 0.858 & 1 \\
& GC+CC & 165 & 181 & & & & $1.184(0.689-2.035)$ \\
& Allele & & & & & & \\
& G & 417 & 460 & 0.039 & 0.843 & 0.858 & 1 \\
& C & 193 & 218 & & & & $0.977(0.772-1.235)$ \\
rs45536634 & GG & 227 & 297 & 9.275 & 0.002 & $0.006^{*}$ & 1 \\
& GA+AA & 62 & 42 & & & & $1.931(1.259-2.963)^{*}$ \\
& Allele & & & 9.545 & 0.002 & $0.006^{*}$ & \\
G & 513 & 635 & & & & 1 \\
A & 65 & 43 & & & & $1.871(1.251-2.798)^{*}$ \\
rs12496815 & GG & 62 & 69 & 1.421 & 0.233 & 0.395 & 1 \\
& GA+AA & 190 & 268 & & & & $0.789(0.534-1.165)$ \\
Allele & & & & & & \\
G & 247 & 308 & 1.268 & 0.263 & 0.395 & 1 \\
A & 257 & 366 & & & & $0.876(0.695-1.103)$ \\
\hline
\end{tabular}

2 adj represent $P$ corrected by FDR

$3 * P_{\text {adj }}<0.05$

4 


\section{Table 4 (on next page)}

Genotype and allele distributions of CACNA2D2 SNPs in male

$P_{\text {adj }}$ represent $P$ corrected by FDR 
1 Table 4. Genotype and allele distributions of $C A C N A 2 D 2$ SNPs in male.

\begin{tabular}{llllllll}
\hline SNPs & Genotype & Case & Control & $\chi^{2}$ & $P$ & $P_{\text {adj }}$ & OR(95\%CI) \\
\hline rs3806706 & GG & 190 & 225 & 5.373 & 0.02 & 0.12 & 1 \\
& GC+CC & 241 & 208 & & & & $1.372(1.050-1.793)$ \\
& Allele & & & & & & \\
& G & 580 & 617 & 3.185 & 0.074 & 0.172 & 1 \\
& C & 282 & 249 & & & & $1.205(0.982-1.478)$ \\
rs45536634 & GG & 361 & 369 & 0.127 & 0.721 & 0.865 & 1 \\
& GA+AA & 67 & 64 & & & & $1.070(0.738-1.552)$ \\
& Allele & & & 0.00025 & 0.987 & 0.987 & \\
G & 786 & 795 & & & & 1 \\
& A & 70 & 71 & & & & $1.997(0.707-1.407)$ \\
rs12496815 & GG & 85 & 105 & 0.66 & 0.416 & 0.624 & 1 \\
& GA+AA & 303 & 327 & & & & $1.145(0.826-1.586$ \\
& Allele & & & & & & \\
G & 347 & 423 & 2.953 & 0.086 & 0.172 & 1 \\
A & 429 & 441 & & & & $1.186(0.976-1.440)$ \\
\hline
\end{tabular}

$P_{\text {adj }}$ represent $P$ corrected by FDR 


\section{Table 5 (on next page)}

Association between haplotypes and schizophrenia by sex

$* P_{\text {adj }}<0.05$ 
Table 5. Association between haplotypes and schizophrenia by sex

\begin{tabular}{|c|c|c|c|c|c|c|c|c|c|c|}
\hline \multirow[b]{2}{*}{ Haplotype } & \multicolumn{5}{|c|}{ Male(frequency) } & \multicolumn{5}{|c|}{ Female(frequency) } \\
\hline & $\begin{array}{l}\text { Contro } \\
1\end{array}$ & Case & OR $(95 \% C I)$ & $P$ & $P_{a d j}$ & Control & Case & OR $(95 \% C I)$ & $P$ & $P_{a d j}$ \\
\hline \multirow{2}{*}{\multicolumn{11}{|c|}{$\begin{array}{l}\text { rs45536634- } \\
\text { rs12496815 }\end{array}$}} \\
\hline & & & & & & & & & & \\
\hline GA & $\begin{array}{l}0.510 \\
5\end{array}$ & $\begin{array}{l}0.551 \\
8\end{array}$ & 1 & - & - & 0.5424 & $\begin{array}{r}0.506 \\
9\end{array}$ & 1 & - & - \\
\hline GG & $\begin{array}{l}0.407 \\
5\end{array}$ & $\begin{array}{l}0.366 \\
6\end{array}$ & $\begin{array}{l}0.84(0.68- \\
1.03)\end{array}$ & $\begin{array}{l}0.08 \\
6\end{array}$ & 0.28 & 0.3942 & $\begin{array}{r}0.380 \\
7\end{array}$ & $1.02(0.80-1.31)$ & 0.87 & 0.87 \\
\hline $\mathrm{AG}$ & 0.082 & $\begin{array}{l}0.081 \\
6\end{array}$ & $\begin{array}{l}0.93(0.66- \\
1.31)\end{array}$ & 0.66 & 0.7 & 0.0634 & $\begin{array}{r}0.112 \\
5\end{array}$ & $1.91(1.26-2.90)$ & $\begin{array}{c}0.002 \\
6\end{array}$ & $\begin{array}{l}0.026 \\
*\end{array}$ \\
\hline AA & 0 & 0 & & - & - & 0 & 0 & & - & - \\
\hline \multicolumn{11}{|l|}{$\begin{array}{l}\text { rs124996815- } \\
\text { rs3806706 }\end{array}$} \\
\hline GG & $\begin{array}{l}0.446 \\
2\end{array}$ & $\begin{array}{l}0.393 \\
3\end{array}$ & 1 & - & - & 0.4098 & $\begin{array}{r}0.419 \\
6\end{array}$ & 1 & - & - \\
\hline AG & $\begin{array}{l}0.265 \\
9\end{array}$ & $\begin{array}{l}0.279 \\
6\end{array}$ & $\begin{array}{l}1.18(0.92- \\
1.51)\end{array}$ & 0.18 & 0.3 & 0.2686 & 0.264 & $0.96(0.71-1.29)$ & 0.77 & 0.87 \\
\hline$A C$ & $\begin{array}{l}0.243 \\
9\end{array}$ & $\begin{array}{l}0.275 \\
2\end{array}$ & $\begin{array}{l}1.27(1.00- \\
1.61)\end{array}$ & $\begin{array}{l}0.04 \\
6\end{array}$ & 0.23 & 0.2742 & $\begin{array}{r}0.247 \\
3\end{array}$ & $0.88(0.66-1.16)$ & 0.37 & 0.74 \\
\hline
\end{tabular}




\begin{tabular}{|c|c|c|c|c|c|c|c|c|c|c|}
\hline GC & 0.044 & $\begin{array}{l}0.051 \\
9\end{array}$ & $\begin{array}{l}1.33(0.77- \\
2.29)\end{array}$ & 0.31 & 0.388 & 0.0473 & $\begin{array}{r}0.069 \\
1\end{array}$ & $1.43(0.77-2.62)$ & 0.26 & 0.65 \\
\hline \multicolumn{11}{|c|}{$\begin{array}{l}\text { rs124996815 } \\
\text { - } \\
\text { rs3806706- } \\
\text { rs45536634 }\end{array}$} \\
\hline GGG & $\begin{array}{l}0.371 \\
2\end{array}$ & $\begin{array}{l}0.314 \\
8\end{array}$ & 1 & - & - & 0.3492 & $\begin{array}{r}0.329 \\
7\end{array}$ & 1 & - & - \\
\hline AGG & 0.266 & $\begin{array}{l}0.279 \\
8\end{array}$ & $\begin{array}{l}1.23(0.95- \\
1.59)\end{array}$ & 0.12 & 0.28 & 0.2683 & $\begin{array}{r}0.259 \\
8\end{array}$ & $1.04(0.76-1.43)$ & 0.79 & 0.87 \\
\hline ACG & $\begin{array}{l}0.243 \\
9\end{array}$ & $\begin{array}{l}0.273 \\
5\end{array}$ & $\begin{array}{l}1.31(1.03- \\
1.69)\end{array}$ & $\begin{array}{l}0.03 \\
1\end{array}$ & 0.23 & 0.2741 & $\begin{array}{r}0.249 \\
6\end{array}$ & $0.97(0.72-1.31)$ & 0.85 & 0.87 \\
\hline GGA & $\begin{array}{l}0.074 \\
9\end{array}$ & $\begin{array}{l}0.078 \\
2\end{array}$ & $\begin{array}{l}1.23(0.83- \\
1.81)\end{array}$ & 0.3 & 0.288 & 0.061 & $\begin{array}{r}0.094 \\
1\end{array}$ & $1.67(1.02-2.72)$ & 0.042 & 0.167 \\
\hline GCG & $\begin{array}{l}0.036 \\
9\end{array}$ & $\begin{array}{l}0.050 \\
2\end{array}$ & $\begin{array}{l}1.58(0.87- \\
2.87)\end{array}$ & 0.14 & 0.28 & 0.045 & $\begin{array}{r}0.048 \\
2\end{array}$ & $1.18(0.60-2.34)$ & 0.63 & 0.87 \\
\hline rare & $\begin{array}{l}0.007 \\
1\end{array}$ & $\begin{array}{l}0.003 \\
5\end{array}$ & $\begin{array}{l}0.72(0.13- \\
3.85)\end{array}$ & 0.7 & 0.7 & 0.0024 & $\begin{array}{r}0.018 \\
6\end{array}$ & $\begin{array}{c}8.05(1.01- \\
64.35)\end{array}$ & 0.05 & 0.167 \\
\hline
\end{tabular}


Figure 1

Fig.1 Linkage disequilibrium (LD) of SNPs within CACNA2D2 in female (A) and male (B), $D^{\prime}$ values were used toestimate the LD between pairwise SNPS
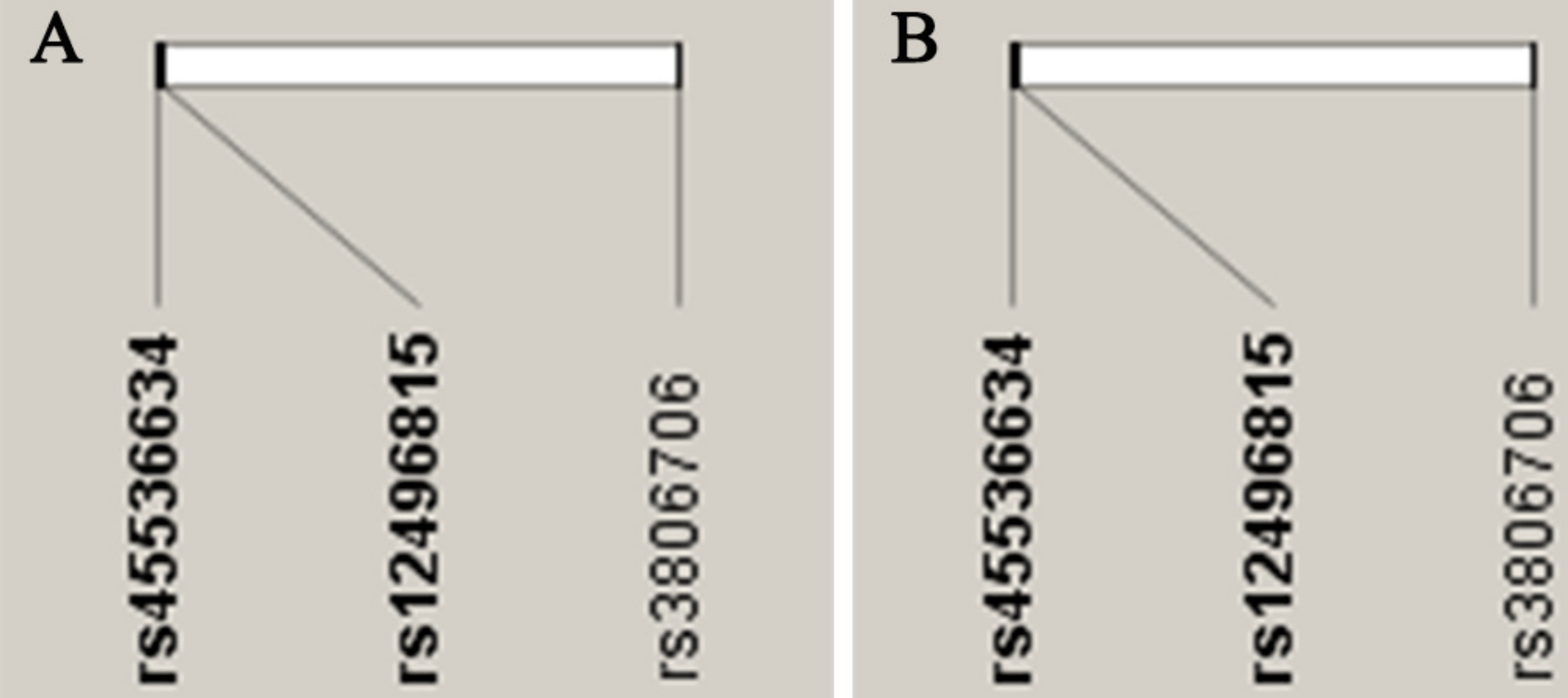

Block $1(1 \mathrm{~kb})$

2

3

5

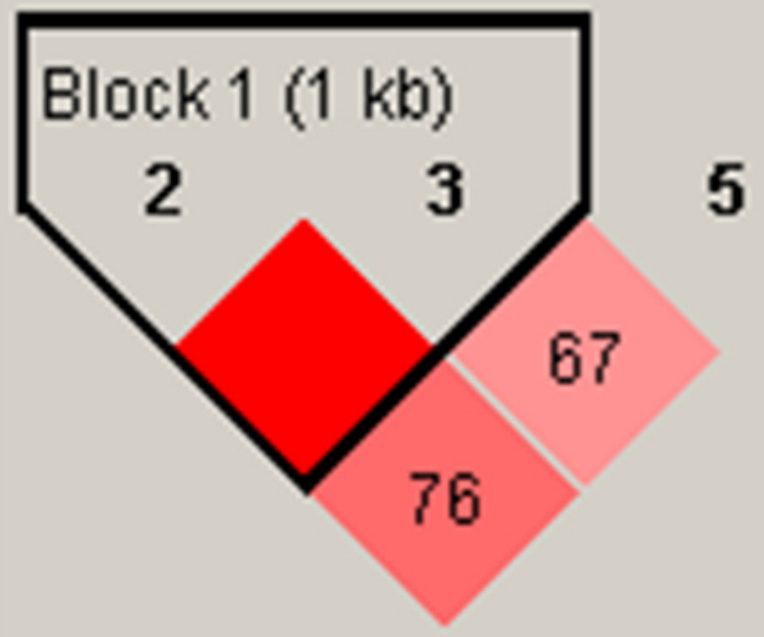

